Rhodes, Muriel E. (1958). J. gen. Microbiol. 18, 639-648

\title{
The Cytology of Pseudomonas spp. as Revealed by a Silver-Plating Staining Method
}

\author{
BY MURIEL E. RHODES \\ Department of Microbiology, University of Reading
}

\begin{abstract}
SUMMARY: A modification of Fontana's silver-plating method was devised and used for the cytological study of 214 isolates of Pseudomonas spp. Many features, such as flagella, cross-walls or septa, capsules and slime were thereby clearly demonstrated simultaneously and easily. Comparisons were made with other published methods for staining flagella, capsules and slime, and good agreement was obtained. No totally non-flagellate isolate was found, nor were flagella lost during maintenance

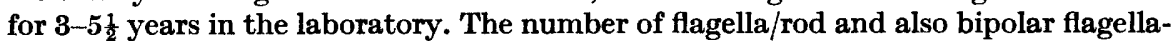
tion were found to be characters of little value for species differentiation. The flagellation of young cultures was not found to be significantly different from that observed in older cultures; the polar position of the flagella was confirmed. Flagella curvature (wavelength and amplitude) as seen in silver-plated organisms prepared under reasonably standardized conditions, was noted and considered to have no usefulness for subgeneric classification.
\end{abstract}

The generic identification of $\boldsymbol{P}$ seudomonas spp. presents little difficulty when the organisms produce the characteristic pigments, but achromogenic strains are common and often not easily distinguishable from Acetobacter, Vibrio, Alcaligenes and Achromobacter spp. (cf. Shewan, Hodgkiss \& Liston, 1954). Since Alcaligenes and Achromobacter are, by family definition, either nonmotile or peritrichously flagellate, a simple method to determine flagellation would be of value. The separation of Pseudomonas and Chromobacterium can also be difficult, but the work of Sneath $(1956 a, b)$ on the latter genus greatly facilitates the diagnosis. Detailed studies of Chromobacterium flagellation were also reported by Sneath $(\mathbf{1 9 5 6} b)$, and his results will be discussed later.

The position and number of flagella/organism are cited in Bergey's Manual (1948) as part of the definitions of Pseudomonas species; these are summarized in Table 1. Therefore it was thought desirable to investigate also the degree of variability in the number of flagella/organism, in order to ascertain the usefulness of this criterion for species differentiation, bearing in mind the value of this character in the classification of algae and phycomycetes. Leifson (1951) suggested, after much experience involving observations of flagella-stained preparations of a large number of different kinds of bacteria, that the degree of curvature (i.e. wavelength and amplitude) of bacterial flagella was perhaps significant, since this character appeared usually to be constant for a given strain; he claimed that in some cases this detail merited consideration even for species or genus definitions. Because many more observations with large numbers of strains are obviously needed, details of flagellation were carefully recorded in the work now to be described. 
Table 1. Summary of the flagellation of the 149 Pseudomonas species (excluding appendices) as listed in Bergey's Manual (1948)

$$
\begin{aligned}
& \text { One polar flagellum } \\
& \text { 1-2 polar flagella } \\
& \text { 1-3 polar flagella } \\
& \text { 1-4 polar flagella } \\
& \text { 1-5 polar flagella } \\
& \text { 1-6 polar flagella } \\
& \text { 1-7 polar flagella } \\
& \text { 1-several polar } \\
& \text { flagella } \\
& \text { 2 polar flagella } \\
& \text { 2-4 polar flagella } \\
& \text { 2-5 polar flagella } \\
& \text { 2-6 polar flagella } \\
& \text { 2-8 polar flagella }
\end{aligned}
$$

Species
42
13
12
9
12
5
1
8

1
5
2
1
1

Species

4-6 polar flagella

5-7 polar flagella

Motile and lopho-

trichous

Motile and polarly

flagellate

Motile (presumably

polar flagellation)

Motile

Non-motile

Not stated

Anomalous (mono-

trichous or 1-3)

1
1
1
15
2
9
6
1
1

\section{METHODS}

Media. The organisms used were maintained in yeast-extract liquid medium or on this medium solidified with agar. The yeast-extract medium had the following composition $(\%, w / v)$ : Oxoid bacteriological yeast extract, 0.3; peptone (Evans), 1.0; $\mathrm{NaCl}, 0.5$; adjusted to $\mathrm{pH} \mathrm{7 \cdot 2-7 \cdot 4}$ with $\mathrm{NaOH}$. For solid medium $2 \cdot 0 \%(\mathrm{w} / \mathrm{v})$ of agar was added.

Growth temperature. All cultures were incubated at $25^{\circ}$, although this was not necessarily the optimum temperature for the growth of every strain.

Source of organisms examined. Two hundred and fourteen isolates of aerobic Gram-negative rod-shaped bacteria, considered likely to be pseudomonads on the basis of various cultural and biochemical characters such as nutrition, temperature range, oxygen requirements, colonial morphology, proteolytic, saccharolytic and lipolytic properties, were obtained from a wide variety of natural sources (human blood and wounds, diseased plants, soil, milk, sewage, many different kinds of water). Nineteen cultures of plant pathogenic Pseudomonas spp. were supplied by Dr W. J. Dowson (Cambridge), and five named cultures were obtained from the National Collection of Type Cultures.

Purification of isolates. Isolates were purified by alternate subcultivation of single colonies in yeast-extract liquid medium and streaking on yeast-extract agar, the process being repeated at least five times.

\section{The staining of flagella}

A modification of Fontana's method for staining spirochaetes (Mackie \& McCartney, 1949, p. 108) was devised, the modifications consisting of slight differences in the reagents and in the method of preparing bacterial films for staining. Two reagents were used:

(1) Ferric tannate mordant. To $10 \mathrm{ml} .10 \%(\mathrm{w} / \mathrm{v})$ tannic acid were added $5 \mathrm{ml}$. saturated aqueous potash alum, followed by $1 \mathrm{ml}$. saturated solution of aniline in water; the curd which formed was re-dissolved by shaking. The 
addition of $1 \mathrm{ml} .5 \%(\mathrm{w} / \mathrm{v})$ ferric chloride gave a black solution which was allowed to stand $10 \mathrm{~min}$. before use.

(2) Ammoniacal silver nitrate solution. From $100 \mathrm{ml}$. of a $5 \%(\mathrm{w} / \mathrm{v})$ aqueous solution of silver nitrate $c .10 \mathrm{ml}$. were set aside. Concentrated ammonia solution (sp.gr. $0 \cdot 880$ ) was slowly added to the $90 \mathrm{ml}$. portion until the brown precipitate just re-dissolved. Drops of the $10 \mathrm{ml}$. sample of silver nitrate solution were then added until the solution remained faintly cloudy, even after shaking. Stored in the dark, this solution remained stable for several weeks.

Method of making a preparation and staining to show flagella. Organisms were grown on yeast-extract agar slopes in $6 \times \frac{5}{8}$ in. tubes, to each of which was added 1-2 ml. sterile distilled water because motile organisms were most readily obtained from the liquid at the base of such slopes. Flagella staining of these cultures was made routinely after 18-24 hr. of incubation, or after $48 \mathrm{hr}$. in the case of the few cultures which grew slowly, e.g. Pseudomonas lachrymans. After incubation, two $4 \mathrm{~mm}$.-loopfuls of the liquid at the base of a slope were inoculated into $5 \mathrm{ml}$. sterile distilled water and incubated for $\mathbf{l} \mathrm{hr} .\left(\mathbf{2 5}^{\circ}\right)$ to remove débris and excess mucilage from the organisms. A drop of this suspension was then transferred to a slide previously cleaned in chromic + sulphuric acid mixture. After allowing the drop to air-dry, the film was covered with the iron tannate mordant reagent (no. 1) for 3-5 min. After very thoroughly washing the film with distilled water the silver reagent (no. 2), heated nearly to boiling, was applied and left in contact with the film for 3-5 min. After again washing the film with distilled water, it was blotted, and either examined directly or made permanent under a coverslip by sealing with neutral Canada Balsam. Exposure to air caused disintegration of these silver-plated preparations after about 1 week. A light microscope with $\frac{1}{12}$ in. oil-immersion objective and $\times 10$ ocular was used to examine the preparations. The silver-plated flagella were found to be easily visible provided that the sub-stage condenser had been carefully centred and focussed. From personal experience it has been found that lack of attention to this technical detail has led many students to believe that flagella staining is difficult. The author found that focusing (under a $\frac{2}{3}$ in. objective) a few threads of cotton wool held in front of the microscope lamp was a simple method for obtaining the necessary optical efficiency.

Each of the Pseudomonas isolates collected was examined at least three times by this flagella-staining technique, after various periods of maintenance (up to $5 \frac{1}{2} \mathrm{yr}$.) as laboratory stock cultures preserved on yeast-extract agar slopes covered with mineral oil (Rhodes, 1957).

Yeast-extract agar + water slope cultures of twelve isolates selected at random were examined by the routine silver-plating technique at hourly intervals up to $18 \mathrm{hr}$. after inoculation of old non-flagellate cultures onto fresh slopes. Thus were investigated the reports of Leifson \& Hugh (1953) and Sneath (1956b) that lateral flagella were found in young cultures of bacteria (Aeromonas and Chromobacterium spp.), but that these cultures yielded only polarly flagellate organisms after longer incubation. 


\section{RESULTS}

Flagellation, slime and capsule formation in 214 pseudomonad isolates

On each slide preparation bearing organisms from one psuedomonad isolate, 200-1000 individual organisms were examined and on many of them polar flagella were frequently clearly visible (see Pl. 1 and Fig. 1). Although occasionally all the organisms in the preparation from a given isolate appeared to be non-flagellate, this was often due to the presence of an excess of slime which spoilt the film : in all these cases a subsequent more dilute preparation, or a slightly older or younger one, showed some polarly flagellate organisms. Thus not one totally non-flagellate isolate of Pseudomonas was found in the collection examined.

\section{Number of flagella/organism}

Table 2 summarizes the results of some of the routine examinations for numbers of flagella, and shows that in the great majority of cases the number of flagella/organism was extremely variable in any given slide preparation.

Table 2. Analysis of the silver-plated preparations of 150 isolates of Pseudomonas to show the variation in the number of flagella/organism

Each preparation was made from a drop of a very dilute aqueous suspension of organisms, and each isolate was examined three times (at various intervals over $5 \frac{1}{2} \mathrm{yr}$.)

Slide preparations showing

All organisms with same number of flagella

Organisms with two different numbers of flagella

Organisms with three different numbers of flagella

Organisms with four different numbers of flagella

Organisms with five different numbers of flagella

Organisms with more than five different numbers of flagella

No flagellate organisms

Number of slide
preparations
examined
90
106
112
89
32
14
7
450

On repeat staining of the 214 isolates the same numbers of flagella/organism as previously recorded were found only for 17 isolates; the remaining 197 isolates showed different values for flagella/organism at the repeat. Plate 1, figs. 1 and 3, show typical microscope fields of preparations in which the different flagellar numbers are clearly visible. In general, rods with small numbers of flagella (1-3) were characteristic, but up to 10 flagella/organism were not uncommon (see Fig. 1 and Pl. 1).

\section{The position of the flagella}

In about $95 \%$ of the individual flagellate organisms examined. the flagella were clearly seen to originate from the rounded polar regions of the rods. Flagella which appeared to be lateral were occasionally observed but, on careful examination, it could often reasonably be interpreted that the dense 


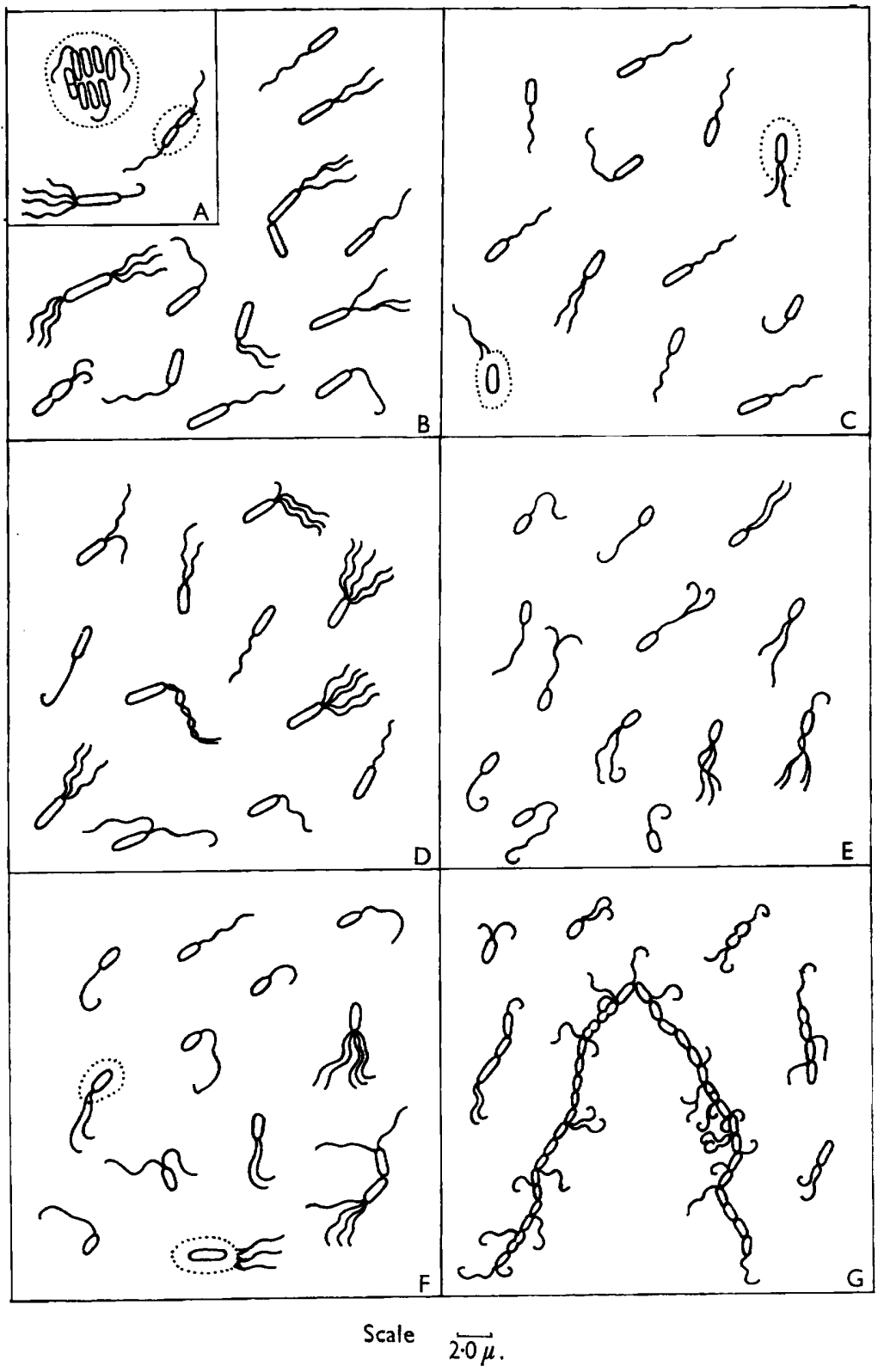

Fig. 1. Depicting the appearance of silver-plated preparations of six isolates of Pseudomonas spp. after $24 \mathrm{hr}$. incubation, and one of these isolates after $10 \mathrm{hr}$. incubation. (The dotted outline indicates the boundary of the capsule.) A. From $10 \mathrm{hr}$. culture of isolate 25/1 : note polar flagella only, variable number of flagella/rod, communal rods in capsules, one rod with cross septum, variable flagella curvature. B. From $24 \mathrm{hr}$. culture of isolate $25 / 1$ : note polar flagella, variable number of flagella/rod, bipolar flagellation, variable flagella curvature. C. From $24 \mathrm{hr}$. culture of isolate 24/1, P. aeruginosa: note tendency to monotrichy, slightly variable flagella curvature, some rods capsulated, flagella arising from the rod and passing through the capsule. D. From $24 \mathrm{hr}$. culture of isolate 13/1: note features as for B. E. From $24 \mathrm{hr}$. culture of isolate 15/1: note features as for B. F. From $24 \mathrm{hr}$. culture of isolate 16/2 : note features as for B. G. From 24. $\mathrm{hr}$. culture of isolate 22/1: note chain formation and apparent lateral flagellation. 
body of the organism was overlaying flagella which originated at a pole. The silver-plating technique also revealed that bicellular organisms with a transverse septum, and longitudinal pairs or chains of organisms, were not uncommon. Each non-septate unit or member of a chain was typically polarly flagellate (see Fig. 1, A, G). In small chains or pairs this may easily be mistaken for lateral flagellation if the staining methods used are not sufficiently refined to show individual cell outlines.

Bipolar flagellation was also noticed fairly frequently (see Fig. 1, A, B); in a total of $\mathbf{4 4 3}$ preparations, 119 showed some organisms with flagella at both poles. This feature was not constant for a given isolate, and it was noticed that it was typically confined to rods of greater than average length, or to rods with distinct signs of a central constriction or septum (see Fig. 1, A, B and $F$ ). Bipolar flagellation thus seems to be a prelude to division, and the listing in Bergey's Manual (1948) of 12 species of Pseudomonas as bipolarly flagel-

late probably has no value in classification, thus supporting the conclusion of Leifson (1951) and Sneath (1956b).

\section{Flagella wavelength and amplitude}

From the examination of many flagellate organisms in each stained preparation, it was evident that the flagella wavelength and amplitude were often not constant even in a single microscope field selected at random. Figure 1 pictures faithful records of flagella observed in a single stained preparation of each of six isolates. It may be seen that a tendency towards a constant flagella spiral was apparent, but variants were common (see also Pl. 1). Because of this visually obvious variability no detailed measurements or analyses were made.

\section{Flagellation of young cultures}

In cultures $0-18 \mathrm{hr}$.-old convincing lateral flagellation was never observed except in association with chain formation or multicellularity. Only rarely were any flagella visible until after $9 \mathrm{hr}$. of incubation, and neither the shape nor position of the flagella of young organisms were especially characteristic. Conspicuous slime and/or capsule formation was however often seen in cultures at $c .10 \mathrm{hr}$. and groups of 2-12 flagellate and non-flagellate rods enclosed in a common capsule were frequently observed (see Fig. 1, A).

\section{Slime and capsule formation}

In young and in older (18-24 hr.) cultures, conspicuous slime formation was often a striking feature of many of these stained preparations, and unless very dilute suspensions were used the whole background of the film after silver plating was dense black; rods were then seen only in a few places where clear zones were apparent round them (see Pl. 1, fig. 2). These clear zones were at first mistaken for capsules; it is possible that they formed as a result of the drying and contraction of hydrophilic colloidal slime away from the organisms. The degree of slime formation varied from this extreme to very slight, but it was very rare for any of the isolates examined to produce no slime at all. It 
was once thought that the stained background was silver-plated mordant, because the application of Klieneberger-Nobel's (1950) technique for staining amorphous slime gave negative results. However, it was noted that one slide which contained preparations from three different isolates simultaneously stained, did not show similar backgrounds, so that an intrinsic difference in the distilled-water suspensions from which the respective smears had been made appeared to be probable. Confirmation that the background material in the silver-plated preparations was indeed amorphous slime was obtained by using the Alcian Blue slime-staining method described by Novelli (1953) and by McKinney (1953) who investigated the polysaccharide specificity of this staining reaction. The results obtained in the present work by using the silver-plating and the Alcian Blue staining techniques were in good agreement.

Distinct and definite zones of darker- or lighter-staining material which surrounded the rods in some of the preparations stained by the silver-plating technique strongly suggested the presence of capsules (see Pl. 1, fig. 3). However, only some organisms in any given preparation showed this feature; the width of the capsular zone was not constant in a given field (see Pl. 1, fig. 3). To confirm that these structures were not artefacts, several methods (Anthony, 1931, modified by Tyler, see Manual of Methods, 1954; Klieneberger-Nobel, 1948, 1950; Leifson, 1951 ; Kulka \& Walker, 1948; Novelli, 1953) for demonstrating capsules were compared, using some mucoid strains of Pseudomonas as test material. In all cases distinct capsulation was shown only by some individual organisms in each preparation; this character did not appear to be very constant or stable and the width of the capsule when seen was also variable.

Protrusion of a flagellum through the capsule was frequently observed (see Pl. 1, fig. 3; Fig. 1, A, C and F). When it was not possible to focus flagella through a capsule, they could be distinguished from fine strands of slime or capsular material which were frequently seen (apparently drawn out from any zone of the capsule) by: (a) the uniform diameter; $(b)$ the regular spiral shape (usually); $(c)$ the darker colour; $(d)$ the polar position. The slime strands are not considered to lend any support to Pijper's (1946) theory of bacterial locomotion.

\section{DISCUSSION}

The flagella-staining method described here may be recommended for the routine examination of Pseudomonas spp. for several reasons, including: no elaborate apparatus or uncommon chemicals are required; the preparations show several cytological features simultaneously, viz. number and position of flagella, chain formation, internal cellular differentiation, slime and capsule formation. During the work reported, comparisons with other flagella-staining methods, e.g. those of Gray (1926) and Leifson (1951), were made, but it was found that these gave a much less refined picture than did the method here advocated. With the former methods the background was usually darker and more granular. Also, individual flagella were not so clearly distinguishable, particularly when more than two were present (as was the case with the typically lophotrichate pseudomonads). 
The exact position of the flagella is considered by many to be useful in bacterial classification. Many thousands of flagellate pseudomonads were observed in the stained preparations described in the present work, and lateral flagella were rarely seen on non-septate rods, although flagella probably partly obliterated by the dense body of the organism and thus apparently emerging laterally, were occasionally seen. In my experience, lateral flagella were associated with rod constrictions, cross-septa or chain formation. Electron micrographs of authentic Pseudomonas spp. (van Iterson, 1947; Bartholomew 1949; Houwink \& van Iterson, 1950; Bisset \& Hale, 1951; Bisset 1951) support this opinion. To my knowledge only Bartholomew (1949) has asserted lateral flagellation in Pseudomonas; after careful examination of his pictures the present writer feels that it is probable that the true origins of the rarely seen lateral flagella were concealed by the dense bodies of the organisms. However, organisms from single pure cultures with polar or lateral flagella, or both, have now been described by several workers: Leifson \& Hugh (1953) for Aeromonas, Alcaligenes and certain yellow bacteria; Leifson \& Palen (1955) for Listeria; Sneath (1956b) for Chromobacterium; Conn \& Elrod (1947) for Rhizobium. Sneath $(1956 b)$ reported an investigation of various environmental factors which might affect flagella location. He found that laterally-flagellate chromobacteria were rare in a liquid medium, that organisms from young cultures frequently had many lateral flagella, but that in older cultures only polar flagella were evident. Sneath's observations strengthen the warning of Leifson \& Hugh (1953) that lateral flagella in the early stages of growth of many bacteria, e.g. Aeromonas (ex Pseudomonas), must be recognized. Leifson \& Hugh suggested that such young peritrichously-flagellate bacteria were multicellular, and that as growth proceeded polarly-flagellate unicells became dominant. Sneath $(\mathbf{1 9 5 6} b)$ rejected this hypothesis after failing to demonstrate more nuclear structures and cross-walls in the peritrichously-flagellate organisms than in the older polarly-flagellate forms. Such observations emphasize the need for a statement of the growth conditions, especially noting the factors known to affect cell division, if the location of bacterial flagella is to be used in classification. The uniform conditions maintained in the present work may account for the consistent polar flagellation observed. The observations described in the present account, including studies of young organisms, confirm the definition of Pseudomonas as a polarly-flagellate genus, but do not support further subdivision on the basis of monotrichous or lophotrichous flagellation (as advocated by Leifson, 1951).

Another detail which has been suggested as worthy of consideration for classification purposes is that of the degree of curvature (wavelength and amplitude) of the flagella (Leifson, 1951; Leifson \& Hugh, 1953; Leifson \& Palen, 1955; Leifson, Carhart \& Fulton (1955). From the results of the present work it is concluded that in Pseudomonas, even under the reasonably standardized conditions used here, differences in flagella wavelength and amplitude are not sufficiently constant to be a useful character for subgeneric classification. This conclusion may be criticized, as indeed the suggestions of Leifson and his colleagues have been criticized (Pijper \& Abraham, 1954; 
Pijper, Neser \& Abraham, 1956), on the grounds that stained pictures of flagella are artefacts because flagella wavelength is affected by varying environmental factors (e.g. temperature, $\mathrm{pH}$ value, colloid content of the medium, drying), which are not constant during the flagella-staining procedure. Much of this criticism is perhaps not valid in the light of Weibull's markedly artefact-producing flagella precipitation experiments, in which pure flagella suspensions or solutions were salted out with ammonium sulphate; in the case of Proteus, the resultant spirals had the same period as the flagella on the living organism (Weibull, 1951). From measurements made on living organisms, Pijper et al. (1956) recorded that at least two wavelengths were found in Pseudomonas; c. $1.53 \mu$. for P. aeruginosa, 1.32 $\mu$. for a Pseudomonus sp., and $0.60 \mu$. for $\boldsymbol{P}$. diminuta. This latter appears a striking difference, but the present writer feels that the creation of this new species of Pseudomonas by Leifson \& Hugh (1954) on the sole basis of the unusual flagella wavelength may be questioned. Indeed the allocation of Leifson \& Hugh's organism to the genus $P$ seudomonas may be queried because of lack of pigment, no acid production from glucose, rapid production of acid (which acid?) from ethanol and the high ethanol tolerance; the genera Vibro and Acetobacter would also seem to qualify for consideration. The desirability of a critical assessment of all known diagnostic characters, together with some comparison with the most nearly related of the numerous $\boldsymbol{P}$ seudomonas species already described, before the creation of further new species of this genus, has already been adequately emphasized by van Niel \& Allen (1952).

The author wishes to thank Dr W. J. Dowson for the gift of nineteen cultures of phytopathogenic Pseudomonas spp., the Curator of the National Collection of Type Cultures for five named cultures and Imperial Chemical Industries Ltd. (Manchester) for a generous sample of Alcian Blue $8 \mathrm{GN}$.150. The photomicrographs were kindly produced by Mr R. A. Barker; to him, and to Professor B. C. J. G. Knight and Dr T. Gibson for their help in the production of this paper, grateful acknowledgement is expressed.

\section{REFERENCES}

Anthony, E. E. (1981). See Manual of Methods for the Pure Culture Study of Bacteria. Leaflet IV. Staining Methods (1954), p. 18.

Bartholomew, J. W. (1949). Flagellation of certain species of Pseudomonas as seen with the electron microscope. J. gen. Microbiol. 3, 340.

Bergey's Manual of Determinative Bacteriology (1948). 6th ed. Edited by Breed, R. S., Murray, E. G. D. \& Hitchens, A. P. London: Baillière, Tindall and Cox.

Brsset, K. A. (1951). The development of the surface structures in dividing bacteria. J. gen. Microbiol. 5, 155.

Bisser, K. A. \& HALE, C. M. F. (1951). The development of bacterial flagella in the germinating microcyst. J. gen. Microbiol. 5, 150.

ConN, H. J. \& ELrod, R. P. (1947). Concerning flagellation and motility. J. Bact. 54,681 .

Gray, P. H. H. (1926). A method of staining bacterial flagella. J. Bact. 12, 273.

Houwink, A. L. \& ItErSON, W. van (1950). Electron microscopical observations on bacterial cytology. II. A study on flagellation. Biochim. Biophys. Acta, 5, 10.

ITERSON, W. VAN (1947). Some electron microscopical observations on bacterial cytology. Biochim. Biophys. Acta, 1, 527. 
KLIENeberger-Nobel, E. (1948). Capsules and mucoid envelopes of bacteria. J. Hyg., Camb. 46, 345.

KuIENEBerger-Nobel, E. (1950). Methods for the study of the cytology of bacteria and pleuropneumonia-like organisms. Quart. J. micr. Sci. 91, 340.

Kulka, D. \& Walker, T. K. (1948). Capsules of Aerobacter turbidans 'demonstrated' by positive staining. J. Inst. Brewing, 54, 148.

LeIfson, E. (1951). Staining, shape and arrangement of bacterial flagella. J. Bact. 62,377 .

Leifson, E., Carhart, S. R. \& Fulton, M. (1955). Morphological characteristics of flagella of Proteus and related bacteria. J. Bact. 69, 73.

Leirson, E. \& Hugh, R. (1953). Variation in shape and arrangement of bacterial flagella. J. Bact. 65, 263.

Leifson, E. \& Hugh, R. (1954). A new type of polar monotrichous flagellation. J. gen. Microbiol. 10, 68.

Leifson, E. \& Palen, M. I. (1955). Variations and spontaneous mutations in the genus Listeria in respect to flagellation and motility. J. Bact. 70, 283.

Mackie, T. J. \& McCartney, J. E. (1949). Handbook of Practical Bacteriology, 8th ed. Edinburgh: E. and S. Livingstone Ltd.

McKrnNey, R. E. (1953). Staining bacterial polysaccharides. J. Bact. 66, 453.

Manual of Methods for the Pure Culture Study of Bacteria. Leaflet IV. Staining Methods (1954). 11th ed. Prepared by Conn, H. J., Bartholomew, J. W. and Jennison, M. W. Geneva, New York: Biotech. Publications.

Niel, C. B. van \& Allen, M. B. (1952). A note on Pseudomonas stutzeri. J. Bact. $64,413$.

Novelli, A. (1953). New method of staining of bacterial capsules in films and sections. Experientia, 9, 34.

Pijper, A. (1946). Shape and motility of bacteria. J. Path. Bact. 58, 325.

Pijper, A. \& Abraham, G. (1954). Wavelengths of bacterial flagella. J. gen. Microbiol. 10, 452 .

PiJper, A., Neser, M. L. \& Abraham, G. (1956). The wavelengths of helical bacterial flagella. J.gen. Microbiol. 14, 371.

Rhones, M. E. (1957). The preservation of Pseudomonas under mineral oil. J. Appl. Bact. 20, 108.

Shewan, J. M., Hodgkiss, W. \& Liston, J. (1954). A method for the rapid differentiation of certain non-pathogenic asporogenous bacilli. Nature, Lond. 173, 208.

SNeath, P. H. A. (1956a). Cultural and biochemical characteristics of the genus Chromobacterium. J. gen. Microbiol. 15, 70.

SNEATH, P. H. A. $(1956 b)$. The change from polar to peritrichous flagellation in Chromobacterium spp. J. gen. Microbiol. 15, 99.

WeIBuld, C. (1951). Movement of bacterial flagella. Nature, Lond. 167, 511.

\section{EXPLANATION OF PLATE}

Pseudomonas spp.; silver-plated preparations of various isolates.

Fig. 1. Isolate 78/2. From 24, hr. culture. Note polarly flagellate rods, different numbers of flagella/organism, occasional apparently lateral flagellation and the tendency toward a uniform flagella curvature. $\times \mathbf{2 5 0 0}$.

Fig. 2. Isolate 74. From $24 \mathrm{hr}$. culture. The dense background is due to abundant exocellular slime. Reasons for the clear zones round the rods are not known, but they are not to be mistaken for capsules. Note flagella. $\times 2500$.

Fig. 3. Isolate $42 / 3$. From $24 \mathrm{hr}$. culture. Note polar flagellation, different numbers of flagella/organism (1-10), amphitrichate rods of larger than average size or showing signs of fission, flagella arising from the rod and passing through the capsule, variable width of capsules, edge of film showing stained exocellular slime, and the slightly variable flagella curvature. $\times 2500$.

(Received 18 November 1957) 
Journal of General Microbiology, Vol. 18, No. 3

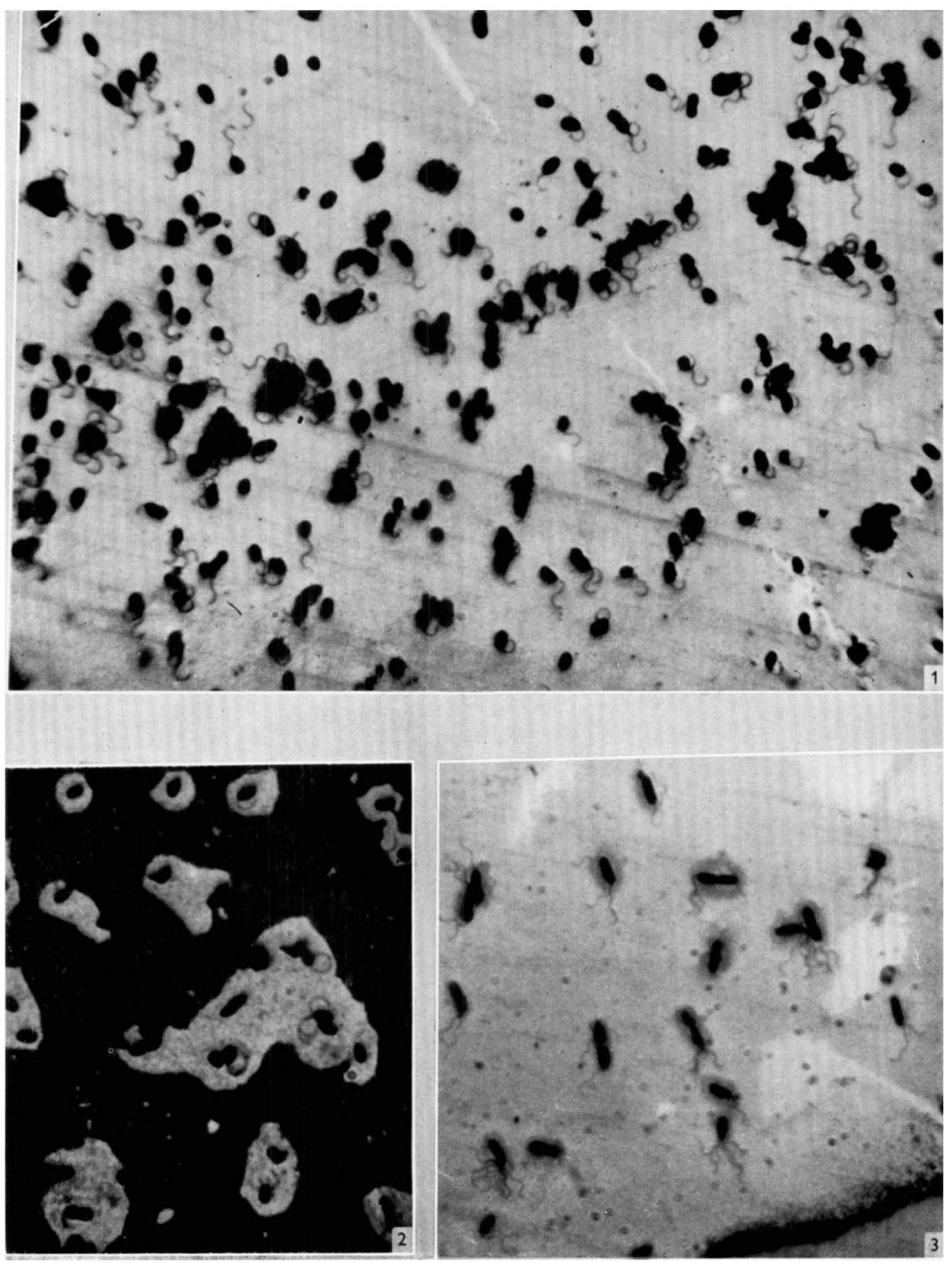

M. E. Rhodes-The cytology of Pseudomonas. Plate 1 